\title{
Effect of dexmedetomidine combined with lumbar anesthesia on Th1/Th2 in maternal patients and neonates undergoing caesarean section
}

\author{
WENTIAN SHI ${ }^{1}$ and PING ZHANG ${ }^{2}$ \\ Departments of ${ }^{1}$ Obstetrics and Gynecology and ${ }^{2}$ Anesthesiology, \\ Liaocheng People's Hospital, Liaocheng, Shandong 252000, P.R. China
}

Received September 5, 2018; Accepted March 29, 2019

DOI: $10.3892 / \mathrm{etm} .2019 .7648$

\begin{abstract}
The selection of anesthetic method and drugs is of utmost importance for patients undergoing caesarean section. The application of anesthetic drugs may affect the immune system of the maternal patient and neonate. Therefore, the present study aimed to analyze the effect of dexmedetomidine combined with lumbar anesthesia on type $1 \mathrm{~T}$-helper cells (Th1) and Th2 cytokines in mothers and their neonates undergoing caesarean section. A total of 60 females with full-term pregnancies and an American Society of Anesthesiologists grade I or II who received caesarean section were selected and equally divided in a randomized manner into a control group receiving lumbar epidural anesthesia and a combination group treated by dexmedetomidine combined with lumbar epidural anesthesia. The visual analogue scale (VAS) score, adverse reactions, traction response and the neonates' Apgar score were compared between the two groups. The levels of interleukin-2 (IL-2), tumor necrosis factor- $\alpha$ (TNF- $\alpha$ ), IL-4 and IL-10 in the blood of mothers and neonates were detected by reverse transcription-quantitative PCR and ELISA. The results indicated no statistically significant difference in the Apgar score between the two groups. The VAS scores, adverse reactions, reduced traction response, as well as IL-2 and TNF- $\alpha$ expression, in the mothers of the combination group were significantly decreased, while IL-4 and IL-10 were obviously elevated compared with those in the controls $(\mathrm{P}<0.05)$. Furthermore, IL-2 and TNF- $\alpha$ levels were markedly declined, whereas IL-4 and IL-10 expression was apparently enhanced in the neonates from the combination group compared with those in the control group $(\mathrm{P}<0.05)$. In conclusion, dexmedetomidine in addition to lumbar epidural anesthesia reduces
\end{abstract}

Correspondence to: Dr Wentian Shi, Department of Obstetrics and Gynecology, Liaocheng People's Hospital, 67 Dongchang West Road, Liaocheng, Shandong 252000, P.R. China

E-mail: ky4km88o280i@sina.com

Key words: caesarean, dexmedetomidine, lumbar epidural anesthesia, Th1, Th2, cytokine the VAS score, adverse reactions and traction response, and promotes the conversion of Th1 cytokines to Th 2 cytokines in mothers/nonates after caesarean section.

\section{Introduction}

Caesarean section is an important obstetric surgery to resolve fetal output of pregnant females who are unable to deliver due to dystocia or certain obstetric complications (1). In developing countries, the proportion of caesarean section in maternal females is exhibiting annual increases, particularly in China (2). The current caesarean section rate in obstetrics and gynecology departments of most hospitals in China has far exceeded the tolerable limit set by the World Health Organization $(3,4)$. In 2004, 29.1\% of neonates were delivered by caesarean section in the United States, which is the highest rate ever reported. The overall rate has increased by $>40 \%$ since 1996, reflecting two concurrent trends: An increase in the primary rate (14.6 to $20.6 \%$ ) and a steep decline in the rate of vaginal birth after caesarean section (28.3 to 9.2\%) (5). Due to the increase in caesarean section and its demand, anesthesia for caesarean section is of utmost importance. Anesthesiologists are required to select appropriate anesthetic drugs, methods and timing to shorten the operation time and reduce the degree of surgical injury to the maternal patient $(6,7)$. Commonly used methods for caesarean section anesthesia mainly include spinal anesthesia, epidural anesthesia, and spinal and epidural combined anesthesia. Among them, lumbar anesthesia is a common method of caesarean section anesthesia $(8,9)$. Lumbar anesthesia has the advantages of simple operation, rapid onset of anesthesia, good abirritation, good muscle relaxation and easy control of the anesthesia level. However, the limitation is short anesthesia time that is not possible to prolong (10-12).

To achieve optimal anesthesia for caesarean section, the selection and combination of anesthetic drugs are crucial factors. Dexmedetomidine belongs to the $\alpha 2$ adrenergic receptor agonists and is relatively selective $(13,14)$. The pharmacological effects of dexmedetomidine include anxiolytic, sedative, analgesic, hypnotic and sympathetic blockade. The US Food and Drug Administration approved the use of dexmedetomidine in mechanical ventilation patients in the adult intensive care unit, as well as in pediatrics, neurosurgery and fiberoptic 
bronchoscopy for cardiovascular surgery $(15,16)$. The application of dexmedetomidine may affect the immune system of the maternal patient and neonate (17). A previous study indicated that dexmedetomidine exerts anti-inflammatory effects through regulation of the type 2 T-helper cell (Th2)-associated cytokines interleukin (IL)-4 and IL-6 (18). However, whether dexmedetomidine administered for caesarean section affects the immune system of maternal patients and neonates has remained largely elusive. Therefore, the present study aimed to investigate the effect of dexmedetomidine combined with lumbar anesthesia on Th1/Th2 cytokines in maternal patients undergoing caesarean section and their neonates.

\section{Patients and methods}

General patient information. A total of 60 full-term maternity patients admitted to the Department of Obstetrics and Gynecology of Liaocheng People's Hospital (Liaocheng, China) who were diagnosed as singleton pregnancies and underwent caesarean section between January 2017 and September 2017 were selected. The fetus was in the head position and complete pre-operative preparations were made to record the relevant clinical data. The patients were all primipara with a mean age of $26.3 \pm 3.5$ years (range, 22-37 years), a mean body weight of $74.7 \pm 6.8 \mathrm{~kg}$ (range, 57-83) and a mean body height of $162.1 \pm 3.4 \mathrm{~cm}$ (range, $152-175 \mathrm{~cm}$ ). The subjects received routine prenatal-associated examinations prior to the surgery, including B-ultrasound and electrocardiogram. The inclusion criterion was an American Society of Anesthesiologists (ASA) grade of I or II (19). The exclusion criteria were maternal eclampsia, an ASA grade of III or IV, preterm infants, multiple pregnancies, contraindications to spinal anesthesia, diabetes mellitus, infections, pregnancy complications (e.g. pregnancy-induced hypertension syndrome), heart disease, history of local anesthetics and opioid allergies, spinal trauma history, blood system problems including coagulation dysfunction, opioid application within one week prior to surgery and pregnancy duration of $>38$ weeks. The present study was approved by the Ethics Committee of Liaocheng People's Hospital (Liaocheng, China). All subjects provided written informed consent.

Major reagents and instruments. TRIzol reagent, RNA extraction kit, PCR primers, High Capacity cDNA Reverse Transcription kit (cat. no. 4368814) and QuantiTect SYBR Green RT-PCR kit were purchased from Invitrogen (Thermo Fisher Scientific, Inc.). IL-2, IL-4, TNF- $\alpha$ and IL-10 ELISA kits were purchased from eBioscience. A Labsystem 1.3.1 microplate reader was obtained from Bio-Rad Laboratories.

Grouping. The subjects were equally and randomly divided into a control group treated by lumbar epidural anesthesia and a combination group treated by dexmedetomidine combined with lumbar epidural anesthesia. Dexmedetomidine was continuously pumped into the L3-L4 space for lumbar epidural anesthesia using a micropump at a dose of $0.8 \mathrm{mg} / \mathrm{kg}$.

Visual analog scale (VAS) score, adverse reactions, traction response and neonates' Apgar score. The traction response was evaluated using the standard for assessing the effect of traction response, as follows: 1 , No perineal or stomach discomfort, no vomiting, nausea or meteorism; 2, mild genital or stomach discomfort, no nausea or vomiting; 3 , perineal pain, stomach discomfort, obvious meteorism, or even nausea and vomiting that requires treatment with drugs. The VAS score ( 0 , no pain; 10 , the greatest pain imaginable) was evaluated $1 \mathrm{~h}$ after surgery and used to assess the pain. After the neonatal outcomes, the Apgar score was assessed by pediatricians at the 1st and 5th minute. Adverse reactions, including nausea, itching, vomiting and respiratory depression, were recorded intra-operatively and at 1,2,6 and $12 \mathrm{~h}$ post-surgery.

Blood sample collection and storage. Blood samples were collected from each group on post-operative day 1. A total of $2 \mathrm{ml}$ blood was collected from the portal vein of the neonates. The sample was centrifuged at $2,000 \mathrm{xg}$ for $15 \mathrm{~min}$ at $4^{\circ} \mathrm{C}$. The serum was placed in an Eppendorf tube and stored at $-20^{\circ} \mathrm{C}$.

Reverse transcription-quantitative $(R T-q) P C R$. Total RNA was extracted from peripheral blood mononuclear cells using TRIzol and reverse transcribed to complementary DNA. The primers were designed by Primer Premier 6.0 (Table I) and synthesized by Sangon Biotech. The PCR thermocycling conditions were as follows: $52^{\circ} \mathrm{C}$ for $1 \mathrm{~min}$, and 35 cycles of $92^{\circ} \mathrm{C}$ for $30 \mathrm{sec}$, $58^{\circ} \mathrm{C}$ for $50 \mathrm{sec}$ and $72^{\circ} \mathrm{C}$ for $35 \mathrm{sec}$. The $2^{-\Delta \Delta \mathrm{Cq}}$ method (20) was applied to calculate the relative expression level.

ELISA. The serum levels of IL-2, IL-4, IL-10 and TNF- $\alpha$ in each group were detected by ELISA. The collected peripheral blood was centrifuged and the supernatant was obtained. The experimental procedure was performed according to the ELISA kit instructions. The $50 \mu$ l diluted standard substance and samples were added to a 96-well plate and incubated at $37^{\circ} \mathrm{C}$ for $30 \mathrm{~min}$. After washing for 5 times, $50 \mu \mathrm{l}$ reagent $\mathrm{A}$ and $50 \mu \mathrm{l}$ reagent $\mathrm{B}$ was added to each well, followed by incubation at $37^{\circ} \mathrm{C}$ for $10 \mathrm{~min}$. Finally, $50 \mu \mathrm{l}$ stop solution was added to each well and the absorbance was read on a microplate reader. A standard curve was prepared to determine the sample concentration based on the optical density value.

Statistical analysis. All data analyses were performed using SPSS 22.0 software (IBM Corp.). Measurement data were expressed as the mean \pm standard deviation and compared by using the unpaired Student's t-test. Correlations were assessed by Pearson's correlation analysis. The test level was set at $\alpha=0.05$. $P<0.05$ was considered to indicate a statistically significant difference.

\section{Results}

Dexmedetomidine decreases the VAS score of maternal females after caesarean section under lumbar anesthesia. The pain in each group was assessed using the VAS scoring method. The results indicated that at $1 \mathrm{~h}$ after surgery, the VAS score in the combination group was significantly lower than that in the lumbar anesthesia control group $(\mathrm{P}<0.05$; Fig. 1).

Dexmedetomidine reduces adverse reactions in females with caesarean section under lumbar anesthesia. Adverse reactions in the control group receiving lumbar anesthesia and in the combination group receiving dexmedetomidine combined 
Table I. Sequences of primers used for PCR.

\begin{tabular}{|c|c|c|}
\hline Gene & Forward (5'-3') & Reverse (5'-3') \\
\hline GADPH & AGTGCCAGCCTCGTCTCATAG & CGTTGAACTTGCCGTGGGTAG \\
\hline IL-2 & CAGAGATCTAAGCAGCGACTT & TGGGACCTCATCTCCGTCA \\
\hline TNF- $\alpha$ & GATCTCCTAAACGGAATAGCG & GACTCTGGCTCAATCCGTC \\
\hline IL-4 & AACGGGCCTAAGGATCTCAAT & TGGCTGCACATCGTCA \\
\hline IL-10 & TCTCAAGAGCGTCAAGATA & АATCTCTCCGTCAATCCT \\
\hline
\end{tabular}

IL, interleukin; TNF, tumor necrosis factor.

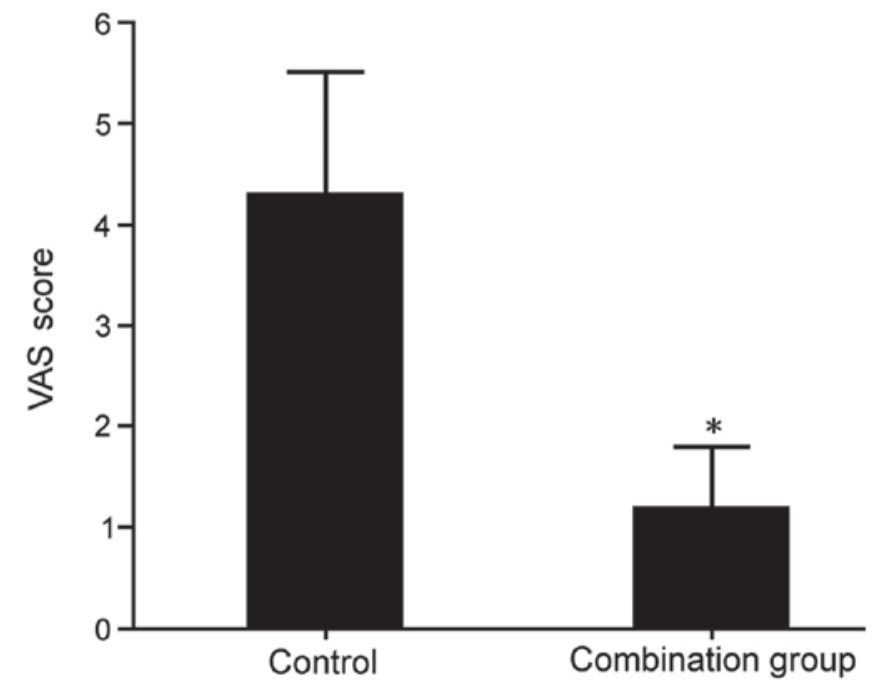

Figure 1. Impact of dexmedetomidine combined with lumbar anesthesia on VAS scores of females with caesarean section. ${ }^{*} \mathrm{P}<0.05$ vs. control. VAS, visual analog scale.

with lumbar anesthesia were observed. It was indicated that dexmedetomidine in addition to lumbar anesthesia obviously reduced the adverse reactions, such as nausea, emesis, shiver and cutaneous pruritus, during caesarean section surgery compared with those in the lumbar anesthesia control group $(\mathrm{P}<0.05$; Table II).

Dexmedetomidine reduces the traction response of females with caesarean section under lumbar anesthesia. The traction response of females with caesarean section was compared between the two groups. The results demonstrated that dexmedetomidine combined with lumbar anesthesia reduced the traction response compared with that in the lumbar anesthesia control group $(\mathrm{P}<0.05$; Table III).

Effect of dexmedetomidine applied during caesarean section combined with lumbar anesthesia on the Apgar score of neonates. No statistically significant difference on the Apgar score of neonates was identified between the two groups (P>0.05; Fig. 2).

Impact of dexmedetomidine combined with lumbar anesthesia during caesarean section on Thl cytokines in maternal females. No significant differences in the levels of TNF- $\alpha$
$(96.3 \pm 6.5 \mathrm{pg} / \mathrm{ml}$ in the control and $95.9 \pm 5.3 \mathrm{pg} / \mathrm{ml}$ in the combination group) and IL-2 $(81.6 \pm 4.7 \mathrm{pg} / \mathrm{ml}$ in the control and $83.5 \pm 4.3 \mathrm{pg} / \mathrm{ml}$ in the combination group) were observed between the two groups prior to surgery. RT-qPCR and ELISA were adopted to test the impact of dexmedetomidine combined with lumbar anesthesia on TNF- $\alpha$ and IL- 2 mRNA and protein levels in the blood of maternal females. The results indicated that dexmedetomidine combined with lumbar anesthesia in females with caesarean section markedly decreased the TNF- $\alpha$ and IL-2 expression and secretion compared with those in the control group ( $\mathrm{P}<0.05$; Figs. 3 and 4$)$.

Impact of dexmedetomidine combined with lumbar anesthesia on Th2 cytokines in maternal females. No significant differences in the levels of IL-4 $(60.3 \pm 3.2 \mathrm{pg} / \mathrm{ml}$ in the control and $64.1 \pm 3.9 \mathrm{pg} / \mathrm{ml}$ in the combination group) and IL-10 $(139.2 \pm 6.1 \mathrm{pg} / \mathrm{ml}$ in the control and $145.3 \pm 8.1 \mathrm{pg} / \mathrm{ml}$ in the combination group) were observed between the two groups prior to surgery. RT-qPCR and ELISA were adopted to determine the impact of dexmedetomidine combined with lumbar anesthesia on IL-4 and IL-10 levels in maternal blood. The results indicated that dexmedetomidine combined with lumbar anesthesia in females with caesarean section promoted the IL-4 and IL-10 mRNA expression and protein secretion compared with those in the control group $(\mathrm{P}<0.05$; Figs. 5 and 6).

Effect of dexmedetomidine combined with lumbar anesthesia on Thl cytokines in neonates. RT-qPCR and ELISA were adopted to test the impact of dexmedetomidine combined with lumbar anesthesia on TNF- $\alpha$ and IL-2 mRNA and protein levels in the blood of neonates. The results indicated that dexmedetomidine combined with lumbar anesthesia caused a significant decline in the TNF- $\alpha$ and IL-2 mRNA expression and protein secretion in neonates compared with those in the control group ( $\mathrm{P}<0.05$; Figs. 7 and 8$)$.

Impact of dexmedetomidine combined with lumbar anesthesia on Th2 cytokines in neonates. RT-qPCR and ELISA were adopted to determine the impact of dexmedetomidine combined with lumbar anesthesia on IL-4 and IL-10 mRNA and protein levels in the blood of neonates. The results indicated that dexmedetomidine combined with lumbar anesthesia promoted the IL-4 and IL-10 mRNA expression and secretion in neonates compared with that in the control group $(\mathrm{P}<0.05$; Figs. 9 and 10). 
Table II. Influence of dexmedetomidine combined with lumbar anesthesia on adverse reactions in females receiving caesarean section.

\begin{tabular}{lccccr}
\hline Group & Bradycardia & Itching & Hypotension & Nausea/vomiting & Total \\
\hline Control $(\mathrm{n}=30)$ & $2(6.6)$ & $5(16.6)$ & $4(13.3)$ & $6(20.0)$ & $17(56.6)$ \\
Combination $(\mathrm{n}=30)$ & $1(3.3)$ & $1(3.3)^{\mathrm{a}}$ & $2(6.6)^{\mathrm{a}}$ & $1(3.3)^{\mathrm{a}}$ & $5(16.6)^{\mathrm{a}}$ \\
\hline
\end{tabular}

${ }^{a} \mathrm{P}<0.05$, compared with control analyzed by chi-square test. Values are expressed as $\mathrm{n}(\%)$.

Table III. Impact of dexmedetomidine combined with lumbar anesthesia on traction response in females with caesarean section.

\begin{tabular}{lccc}
\hline & \multicolumn{3}{c}{ Traction response score } \\
\cline { 2 - 4 } Group & 1 & 2 & 3 \\
\hline Control $(\mathrm{n}=30)$ & $15(50)$ & $11(16.7)$ & $4(13.3)$ \\
Combination $(\mathrm{n}=30)$ & $27(90)^{\mathrm{a}}$ & $2(6.7)^{\mathrm{a}}$ & $1(3.3)^{\mathrm{a}}$ \\
\hline
\end{tabular}

${ }^{\mathrm{a}} \mathrm{P}<0.05$, compared with control analyzed by chi-square test. Values are expressed as $\mathrm{n}(\%)$.

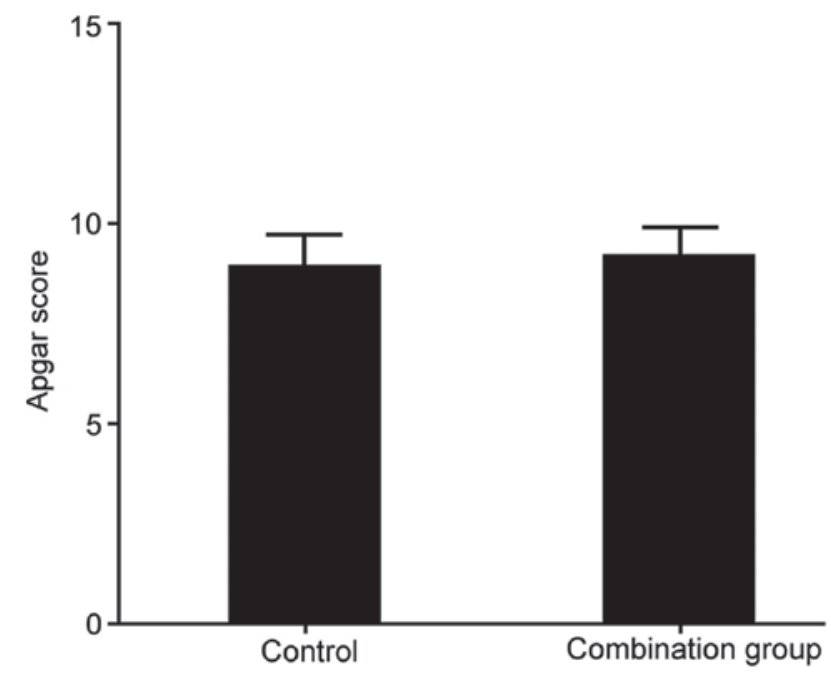

Figure 2. Effect of dexmedetomidine combined with lumbar anesthesia on the Apgar score of neonates after caesarean section.

\section{Discussion}

Dexmedetomidine is used in the clinic for analgesia, sedation and reduction of anesthetic agents. Reasonable application of anesthetics may reduce the occurrence of post-operative complications and rapidly exert anesthetic effects to achieve timely recovery and promote the improvement and recovery of spinal cord injury (21). Although dexmedetomidine is not recommended for pregnant females, a previous study indicated that appropriate doses of dexmedetomidine are beneficial for sedation of pregnant subjects (22). In addition, dexmedetomidine was reported to regulate immune

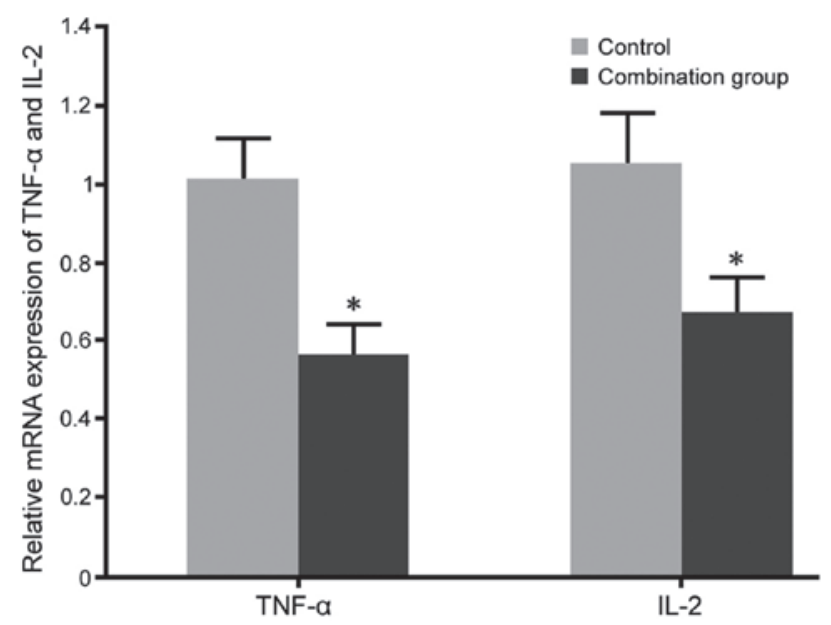

Figure 3. Impact of dexmedetomidine combined with lumbar anesthesia on TNF- $\alpha$ and IL-2 mRNA expression in maternal females after caesarean section. ${ }^{*} \mathrm{P}<0.05$ vs. control. IL, interleukin; TNF, tumor necrosis factor.

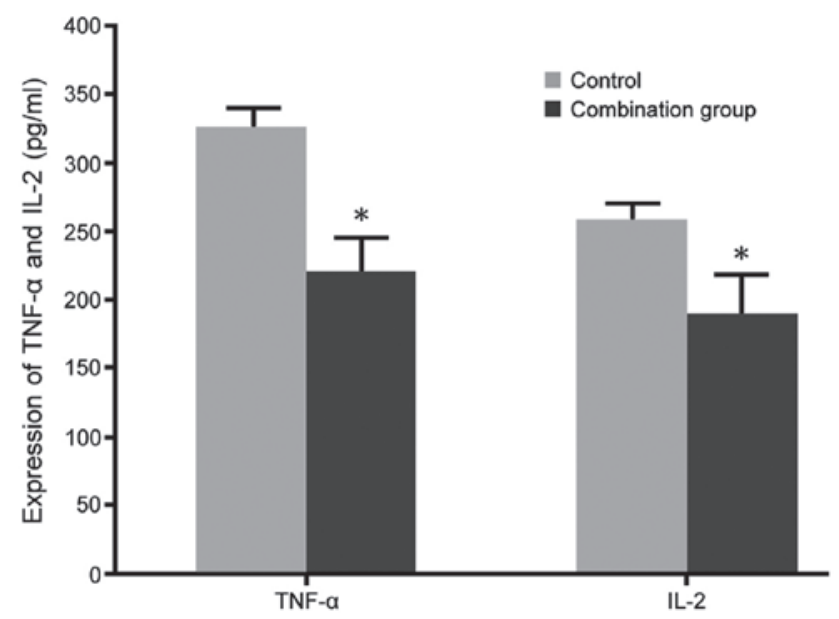

Figure 4. Impact of dexmedetomidine combined with lumbar anesthesia on TNF- $\alpha$ and IL-2 secretion in maternal females after caesarean section. "P<0.05 vs. control. IL, interleukin; TNF, tumor necrosis factor.

suppression, which is caused by surgery-associated stress (23). In the present study, the effects of dexmedetomidine combined with lumbar anesthesia were compared with those of lumbar anesthesia alone on maternal females receiving caesarean section and their neonates. The results indicated that dexmedetomidine combined with lumbar anesthesia reduced the VAS scores, adverse reactions and traction responses without affecting neonatal Apgar scores. These results suggest that 


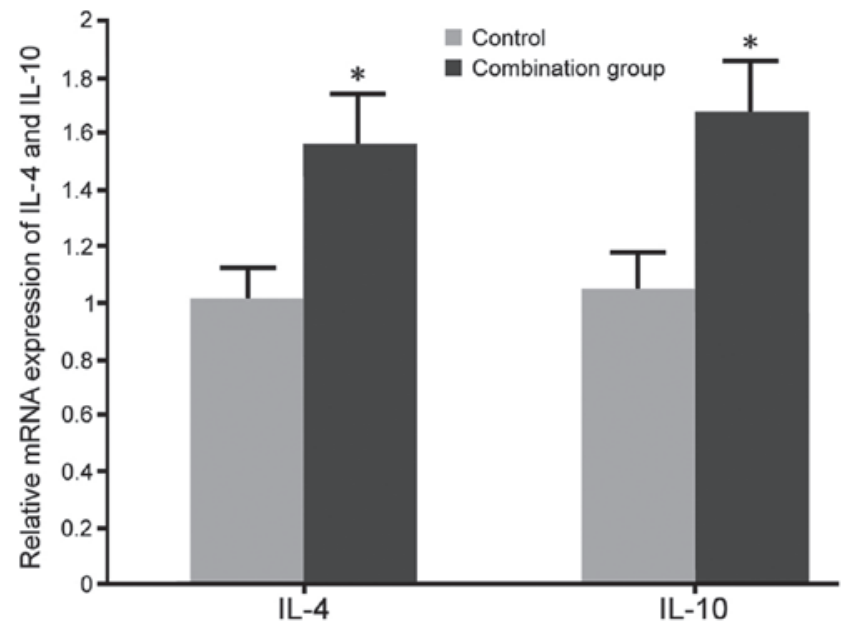

Figure 5. Impact of dexmedetomidine combined with lumbar anesthesia on IL-4 and IL-10 mRNA expression in maternal females after caesarean section. ${ }^{*} \mathrm{P}<0.05$ vs. control. IL, interleukin.

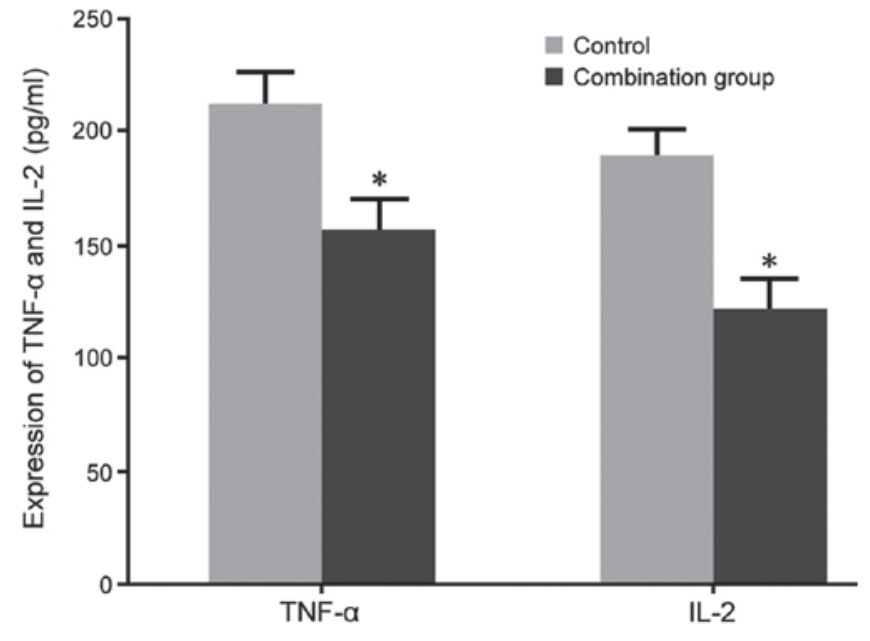

Figure 8. Impact of dexmedetomidine combined with lumbar anesthesia for caesarean section on TNF- $\alpha$ and IL-2 secretion in neonates. ${ }^{~} \mathrm{P}<0.05$ vs. control. IL, interleukin; TNF, tumor necrosis factor.

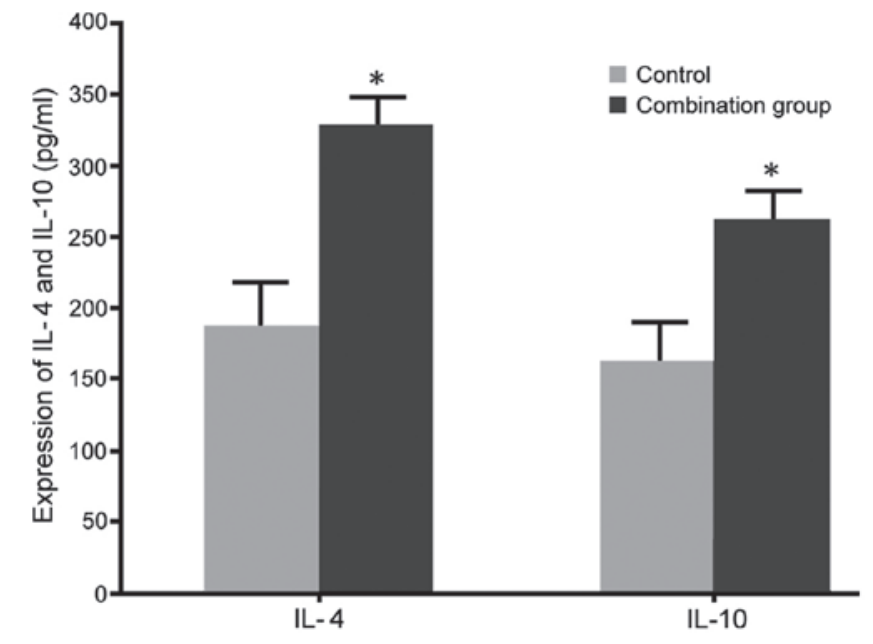

Figure 6. Impact of dexmedetomidine combined with lumbar anesthesia on IL-4 and IL-10 secretion in maternal females after caesarean section. ${ }^{*} \mathrm{P}<0.05$ vs. control. IL, interleukin.

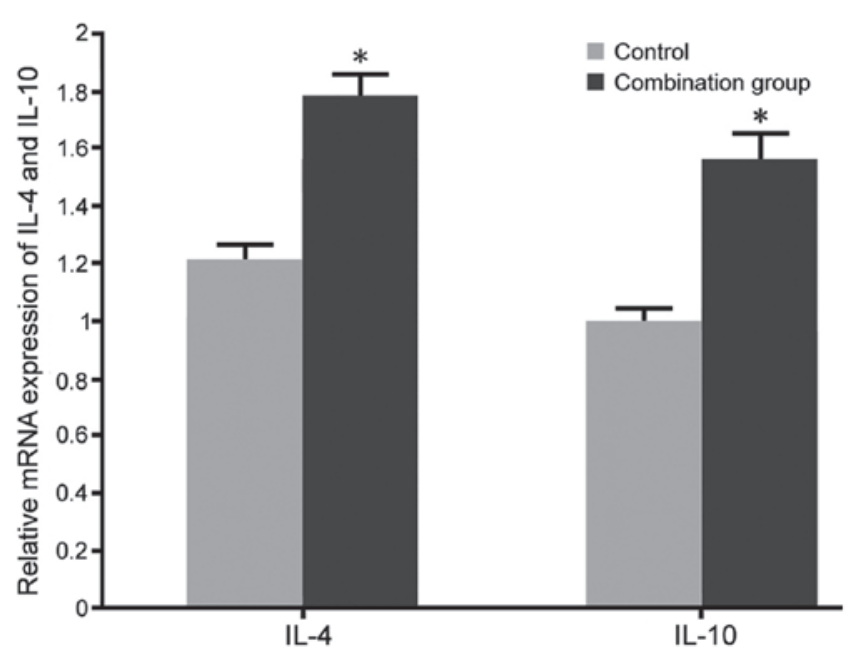

Figure 9. Impact of dexmedetomidine combined with lumbar anesthesia for caesarean section on IL-4 and IL-10 mRNA expression in neonates. ${ }^{*} \mathrm{P}<0.05$ vs. control. IL, interleukin.

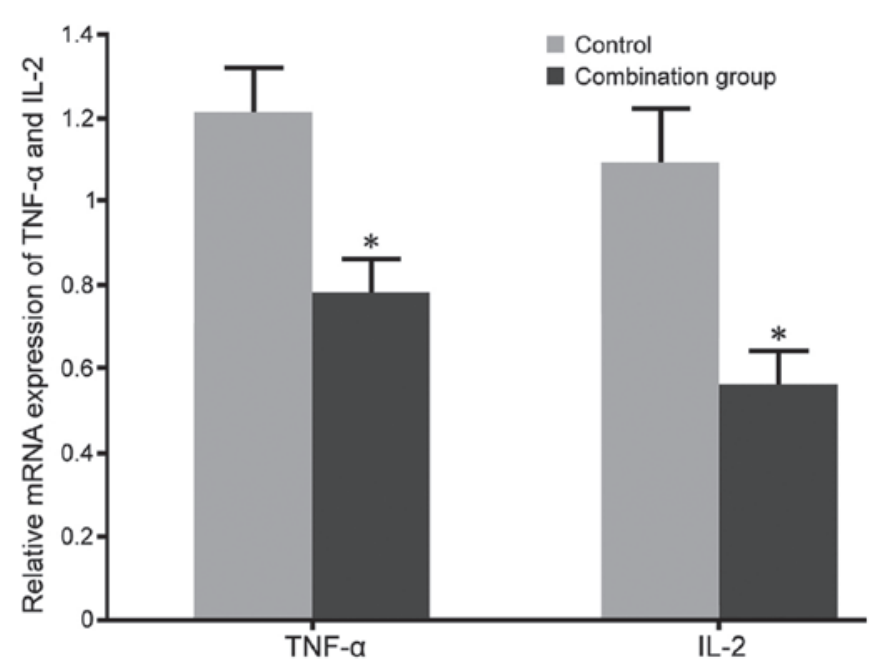

Figure 7. Impact of dexmedetomidine combined with lumbar anesthesia for caesarean section on TNF- $\alpha$ and IL-2 mRNA expression in neonates. ${ }^{*} \mathrm{P}<0.05$ vs. control. IL, interleukin; TNF, tumor necrosis factor.

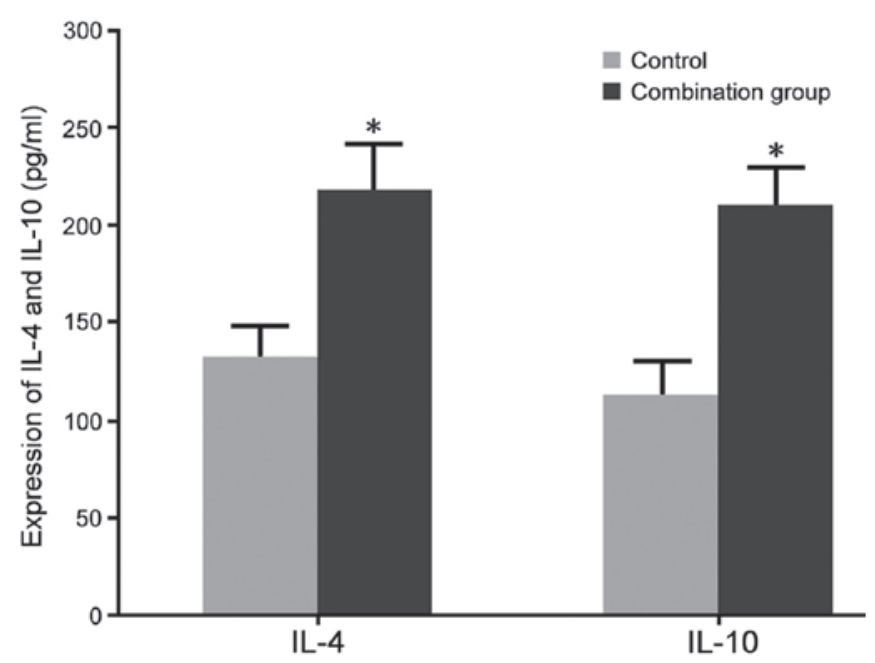

Figure 10. Impact of dexmedetomidine combined with lumbar anesthesia for caesarean section on IL-4 and IL-10 secretion in neonates. ${ }^{*} \mathrm{P}<0.05$ vs. control. IL, interleukin. 
dexmedetomidine combined with lumbar anesthesia enhances the anesthetic effect and promotes recovery of maternal patients after caesarean section.

Post-operative anesthesia-associated complications are one of the problems that affect the surgical process and post-operative recovery of caesarean section patients, mainly including pruritus, post-operative pain, respiratory depression, chills and hypotension $(24,25)$. However, in the present study, the use of dexmedetomidine combined with lumbar anesthesia was indicated to reduce adverse reactions and traction response. The increased secretion of the Th1 inflammatory factors IL-2 and TNF- $\alpha$ activates the inflammatory response and facilitates leukocyte adhesion, providing conditions for the further development of inflammation $(26,27)$. The Th2 cytokines IL-4 and IL-10 antagonize Th1 inflammatory cytokines, and suppress the Th1 response and subsequent release of associated factors to enhance the humoral immune response (28). Wegmann et al (29) first postulated the concept that a shift from a Th1 response to a Th2 bias occurs during pregnancy, which functionally induces maternal immune tolerance and suppression. Several clinical studies have demonstrated a Th2 bias in the circulating Th cytokine profile in normal pregnancies, and an increase in the Th1 ratio in cases of recurrent miscarriage (30) and in preeclampsia (31). The present study demonstrated that dexmedetomidine combined with lumbar anesthesia resulted in decreased expression of IL-2 and TNF- $\alpha$, and increased expression of IL-4 and IL-10 in maternal females after caesarean section and their neonates compared with those who had received lumbar anesthesia alone. Although caesarean section may influence the level of IL-2 and IL-4, no significant differences compared with pregnant women with normal delivery have been reported (32). In the present study, all participants received caesarean section; therefore, the changes of IL-2 and IL-4 are due to the different anesthetic treatments. The changes in Th1/Th2 cytokines observed in the present study indicate that dexmedetomidine combined with lumbar anesthesia modulates the Th1/Th2 balance and inhibits Th1 cell differentiation, consistent with a previous study demonstrating that dexmedetomidine inhibited inflammation through upregulation of the Th2-associated cytokines IL-4 and IL-6 (18). However, the exact mechanisms of how dexmedetomidine modulates the Th1/Th2 balance in maternal females receiving caesarean section and their neonates require further elucidation.

In conclusion, dexmedetomidine in addition to lumbar epidural anesthesia reduces the maternal VAS score, adverse reactions and traction response, as well as promotes the conversion of Th1 cytokines to Th2 cytokines in maternal females receiving caesarean section and their neonates.

\section{Acknowledgements}

Not applicable.

\section{Funding}

No funding received.

\section{Availability of data and materials}

Not applicable.

\section{Authors' contributions}

WS and PZ performed the experiments and analyzed the data. WS designed the study and wrote the manuscript.

\section{Ethical approval and consent to participate}

The present study was approved by the Ethics Committee of Liaocheng People's Hospital (Liaocheng, China). All subjects provided written informed consent.

\section{Patient consent for publication}

Not applicable.

\section{Competing interests}

The authors declare that they have no competing interests.

\section{References}

1. Poli-Neto OB, Campos Martins Chamochumbi C, Toscano P, Pitanguy Julio M, Marques W Jr, Rosa-E-Silva JC, Candido-Dos-Reis FJ and Nogueira AA: Electromyographic characterization of abdominal wall trigger points developed after caesarean section and response to local anaesthesia: An observational study. BJOG 125: 1313-1318, 2018.

2. Feng XL, Xu L, Guo Y and Ronsmans C: Factors influencing rising caesarean section rates in China between 1988 and 2008. Bull World Health Organ 90: 30-39, 39A, 2012.

3. Singal S, Bharti R, Dewan R, Divya, Dabral A, Batra A, Sharma M and Mittal P: Clinical outcome of postplacental copper T 380A insertion in women delivering by caesarean section. J Clin Diagn Res 8: OC01-OC04, 2014.

4. Ozkan Seyhan T, Orhan-Sungur M, Basaran B, Savran Karadeniz M, Demircan F, Xu Z and Sessler DI: The effect of intra-abdominal pressure on sensory block level of single-shot spinal anesthesia for cesarean section: An observational study. Int J Obstet Anesth 24: 35-40, 2015.

5. Menacker F, Declercq E and Macdorman MF: Cesarean delivery: Background, trends and epidemiology. Semin Perinatol 30: 235-241, 2006.

6. El-Agwany AS: Considerable observations in cesarean section surgical technique and proposed steps. Arch Gynecol Obstet 297: 1075-1077, 2018.

7. Liu C, Sun W, Wang C, Liu F and Zhou M: Delivery during extracorporeal membrane oxygenation (ECMO) support of pregnant woman with severe respiratory distress syndrome caused by influenza: A case report and review of the literature. J Matern Fetal Neonatal Med 32: 2570-2574, 2019.

8. Shi YC, Guo H, Chen J, Sun G, Ren RR, Guo MZ, Peng LH and Yang YS: Initial meconium microbiome in Chinese neonates delivered naturally or by cesarean section. Sci Rep 8: 3255, 2018.

9. Carness JM and Lenart MJ: Spinal anaesthesia for cesarean section in a patient with vascular type ehlers-danlos syndrome. Case Rep Anesthesiol 2018: 1924725, 2018.

10. Yamashita A and Irikoma S: Comparison of inflationary non-invasive blood pressure (iNIBP) monitoring technology and conventional deflationary non-invasive blood pressure (dNIBP) measurement in detecting hypotension during cesarean section. JA Clin Rep 4: 5, 2018.

11. Nishio Y, Hiraki T, Taniguchi $\mathrm{H}$ and Ushijima K: Anesthetic management during a cesarean section in a patient with cleidocranial dysplasia: A case report. JA Clin Rep 4: 2, 2018.

12. Bard M, Bersot Y, Legros V, Raimond E and Malinovsky JM: Hemodynamic monitoring by the aortic velocity-time integral in supra sternal Doppler echocardiography and total cavo-pulmonary derivation in cesarean delivery. J Clin Anesth 46: 99-100, 2018.

13. Eskandr AM,Metwally AA, Ahmed AA,Elfeky EM,Eldesoky IM, Obada MA and Abd-Elmegid OA: Dexmedetomidine as a part of general anaesthesia for caesarean delivery in patients with pre-eclampsia: A randomised double-blinded trial. Eur J Anaesthesiol 35: 372-378, 2018. 
14. Fan L, Zhang J, Lv Z, Guo H and Zhao Y: Clinical research on the dexmedetomidine applied for patient-controlled sedation during the lower limbs operation under combined spinal-epidural anesthesia. Pak J Pharm Sci 29: 1095-2100, 2016.

15. Sayed E and Yassen KA: Intraoperative effect of dexmedetomidine infusion during living donor liver transplantation: A randomized control trial. Saudi J Anaesth 10: 288-294, 2016.

16. Das A, Chhaule S, Bhattacharya S, Basunia SR, Mitra T, Halder PS, Chattopadhyay S and Mandal SK: Controlled hypotension in day care functional endoscopic sinus surgery: A comparison between esmolol and dexmedetomidine: A prospective, double-blind and randomized study. Saudi J Anaesth 10: 276-282, 2016.

17. Conti G, Ranieri VM, Costa R, Garratt C, Wighton A, Spinazzola G, Urbino R, Mascia L, Ferrone G, Pohjanjousi P, et al: Effects of dexmedetomidine and propofol on patient-ventilator interaction in difficult-to-wean, mechanically ventilated patients: A prospective, open-label, randomised, multicentre study. Crit Care 20: 206, 2016

18. Li B, Li Y, Tian S, Wang H, Wu H, Zhang A and Gao C: Anti-inflammatory effects of perioperative dexmedetomidine administered as an adjunct to general anesthesia: A Meta-analysis. Sci Rep 5: 12342, 2015.

19. Doyle DJ and Garmon EH: American Society of Anesthesiologists Classification (ASA Class). StatPearls [Internet]. Treasure Island (FL): StatPearls Publishing; 2019, Jan 19.

20. Livak KJ and Schmittgen TD: Analysis of relative gene expression data using real-time quantitative PCR and the 2(-Delta Delta C(T)) method. Methods 25: 402-408, 2001.

21. Yuan F, Fu H, Yang P, Sun K, Wu S, Lv M, Dong Z and Dong T: Dexmedetomidine-fentanyl versus propofol-fentanyl in flexible bronchoscopy: A randomized study. Exp Ther Med 12: 506-512, 2016.

22. Nair AS and Sriprakash K: Dexmedetomidine in pregnancy: Review of literature and possible use. J Obstetric Anaesthesia Critical Care 3: 3-6, 2013.

23. Wang L, Zhang A, Liu W, Liu H, Su F and Qi L: Effects of dexmedetomidine on perioperative stress response, inflammation and immune function in patients with different degrees of liver cirrhosis. Exp Ther Med 16: 3869-3874, 2018.
24. Bawdane KD, Magar JS and Tendolkar BA: Double blind comparison of combination of $0.1 \%$ ropivacaine and fentanyl to combination of $0.1 \%$ bupivacaine and fentanyl for extradural analgesia in labour. J Anaesthesiol Clin Pharmacol 32: 38-43, 2016.

25. Kundra TS, Nagaraja PS, Singh NG, Dhananjaya M, Sathish N and Manjunatha N: Effect of dexmedetomidine on diseased coronary vessel diameter and myocardial protection in percutaneous coronary interventional patients. Ann Card Anaesth 19: 394-398, 2016.

26. Jeong SI, Shin JA, Cho S, Kim HW, Lee JY, Kang JL and Park EM: Resveratrol attenuates peripheral and brain inflammation and reduces ischemic brain injury in aged female mice. Neurobiol Aging 44: 74-84, 2016.

27. Elmoutaz Mahmoud $\mathrm{H}$ and Rashwan DAE: Efficacy of dexmedetomidine versus ketofol for sedation of postoperative mechanically ventilated patients with obstructive sleep apnea. Crit Care Res Pract 2018: 1015054, 2018.

28. Lee CH, Park JH, Ahn JH and Won MH: Effects of melatonin on cognitive impairment and hippocampal neuronal damage in a rat model of chronic cerebral hypoperfusion. Exp Ther Med 11: 2240-2246, 2016

29. Wegmann TG, Lin H, Guilbert L and Mosmann TR: Bidirectional cytokine interactions in the maternal-fetal relationship: Is successful pregnancy a TH2 phenomenon? Immunol Today 14: 353-356, 1993

30. Druckmann R and Druckmann MA: Progesterone and the immunology of pregnancy. J Steroid Biochem Mol Biol 97: 389-396, 2005.

31. Lin H, Mosmann TR, Guilbert L, Tuntipopipat S and Wegmann TG: Synthesis of T helper 2-type cytokines at the maternal-fetal interface. J Immunol 151: 4562-4573, 1993.

32. Werlang ICR, Mueller NT, Pizoni A, Wisintainer H, Matte U, Costa SHAM, Ramos JGL, Goldani MZ, Dominguez-Bello MG and Goldani HAS: Associations of birth mode with cord blood cytokines, white blood cells and newborn intestinal bifidobacteria. PLoS One 13: e0205962, 2018. 